\title{
Ethiopian traditional dance alter the health-related physical fitness traits of high school students
}

\section{Soumitra Mandal®, Mulay Gebretensay ${ }^{\circledR}$, Kesatie Legesse®, Menasebo Gebru®, Reagan Kebede (1)}

Department of Sport Science, College of Natural and Computational Sciences, Mekelle University, Mekelle, Ethiopia.

\begin{abstract}
The purpose of this study was to evaluate the effect of Tigray regional state traditional dances on health-related physical fitness traits among high school students in Ethiopia. To achieve the purpose of this study, 100 high school students were selected randomly. And their age was $15.5 \pm 1.1$ years. The selected participants were categorized into the experimental group consists of four Traditional dances that were Awris, Hura, Kuda, and Shediva and the control group with twenty subjects in each. The experimental group performed traditional dances for 16 weeks three days per week whereas participants in the control group were informed to follow their usual daily activity. All participants were tested on selected criterion measures on muscular strength, flexibility, cardiovascular endurance and body composition before and after the 16 weeks of the training period. The data about the variables in this study were statistically examined using ANOVA for each variable separately, whenever the ' $F$ ' ratio of adjusted post-test was found to be significant, the Scheffe's test was used to determine the paired mean differences. The level of significance was fixed at 0.05 . Following the 16-weeks traditional dance training, a significant change was observed on muscular strength, flexibility, and cardiovascular endurance, but there was no significant improvement in body composition as compares to the experimental groups with the control group. Therefore it can be concluded that Tigray traditional dance training program can notably improve physical fitness level of high school students.
\end{abstract}

Keywords. Awris, body composition, cardiovascular endurance, Shediva.

\section{Introduction}

Health and fitness allow people to live longer and they add to the quality of everyday life. So to enjoy an optimal state of health and physical fitness, exercises are quite indispensable. Exercises help maintain the sound body throughout life. As several studies have proved that, the human body can be strengthened by physical activity and can also be impaired by physical inactivity (Almond, 2010). Therefore, as an aerobic exercise, Traditional dance brings well-known benefits in improving the healthrelated components of physical fitness. Dance as a form of exercise is suitable for all ages as it seems to have a particularly beneficial effect on physical health (Lykesas et al., 2017). Dance helps participants develop physical fitness and thus shares many of the health benefits of other sporting events (Nhamo \& Magonde, 2013). Folk dance training can significantly improve the physical fitness level of per-Scholl children (Biber et al., 2016).

Furthermore, Chinese Traditional dance training can improve flexibility, cardiorespiratory endurance, and muscle strength of collegelevel students (Nordin et al., 2009; Moyi Li et al., 2015). Dance can increase people's physical 
fitness, strength and abilities, often more effectively than other forms of exercise, increase people's motivation to participate in physical activity and maintain that participation, because they see dance as fun, expressive, noncompetitive and sociable (Public Health - South West, 2020).

The Go Dance Research Project (Elsa Urmston, Dr Angel Chater, 2012) commissioned by a consortium of dance organization examine the impact of 12 weeks dance course training and consequently found a positive impact on the healthy lives of boys and girls. Other results from this study indicate that, participating in a dance project during school time can inspire positive behavior and change in terms of physical activity levels.

Dance is a popular recreational activity for people and can contribute to the physical health and wellness of an individual (Gardner et al., 2008). As there is growing concern over the effects of the sedentary lifestyle on the health of young people (Biddle et al., 2004), physical activity via behavior such as dancing should be encouraged. However, it is seldom used as an intervention to increase physical activity even among studies advocating culturally-specific interventions (Farr, 1997). As a result, empirical data about a culturally-specific dance intervention to generate health benefits and reduce health disparities common in sedentary African American women is paramount (Murrock \& Gary, 2010).

Traditional dance is one of the most common types of aerobic exercise practices in the world. Presently, dance is a popular activity, performed by small groups of all ages. Music with slow or fast rhythm tempos helps to control and pace the movement of selected body segments, allowing for an overall body workout. As with other forms of aerobic exercise, dance performed within a target heart rate of between $60 \%$ to $80 \%$ of the maximal heart rate (MHR) has demonstrated cardiovascular and metabolic benefits such as increased maximal oxygen consumption $\left(\mathrm{VO}_{2} \mathrm{Max}\right)$, improved aerobic endurance capacity, decreased percent fat and increased energy production via the mitochondrial respiration system (ACSM, 1998).

As several studies have proved that traditional dance can significantly increase the health-related physical fitness variables of students (Gebretensay et al., 2015). However, there is little epidemiological data on the effect of traditional dance practicing on health-related physical fitness variables in Ethiopian adolescences. Therefore, the purpose of the present study was to evaluate the effect of Traditional dances of Tigray regional state i.e.,Awris, Hura, Kuda and Shediva, on healthrelated physical fitness variables, namely, muscular strength, flexibility, cardiovascular endurance and body composition. Hopefully, the implication of such study will enrich the information about the relation of traditional dances with health-related physical fitness variables. Furthermore, it may assist and urge sport science teachers, psychologists, health care experts, coaches, athletes and individuals to incorporate traditional dance programes in their strategies in physical exercise programs aiming at improving the health-related physical fitness variables.

\section{Methods}

For the purpose of the present study, the total of 100 healthy boys and girls (age $15-17$ years) volunteered. They were randomly selected out of a total of 207 students from grade nine and ten of Mekelle University community school using the scientific sample determination technique, namely the Thompson's(2012) formula: $\boldsymbol{n}=\frac{1}{\frac{1}{n \mathbf{0}}+\frac{1}{N}}$ Where: $\mathrm{n}$ is sample size; $\mathrm{n}_{\mathrm{o}}$ is before considering the sample; $\mathrm{N}$ is total population; Confidence 
level was 95\%; Precision level was $\pm 7 \%$; Maximum variability was 0.5 .

The study was approved by the Ethical Review committee of Ayder Referral Hospital of Mekelle University. During the intervention participants were informed to withdraw from the study at any time. The aim and procedure of the study was clear to them during the briefing session of the Consent and Assent form that the participants and their parents or guardian was obtained. The participants and their parents or guardians were assured of their anonymity and confidentiality will be maintained at all times.

Furthermore, the dance professionals and the researcher must avoid hurting the participant's through-out the research any means. During each session the participants undergo through warming up and cool down procedure to prevent physical injury. A warm and friendly environment was created and the researcher was act in the best interest of each participants. Another important ethical consideration was that, professionals must respect the right and dignity as well as the attitude, beliefs and opinions of the participants.

Lastly, the intervention with each participant was carried out in sensitive manner and no pressure was placed on them to do anything with which they did not feel comfortable.

\section{Study Design}

Randomized controlled parallel trial was used for this study because it was considered the most appropriate (Marquez et al., 2014) and (SerranoGuzman, 2016). All the 100 participants were randomly categorized into four experimental and one control group, each group consists of twenty participants $(n=20)$. The experimental group was given the four traditional dances of Tigray regional state (Awris, Hura, Kuda and Shadiva) for a period of sixteen weeks excluding the period of utilized for pre-test and post-test. The control group was not participated in any training program during the experimental period.

\section{Training Protocol}

The dance styles used were characterized as a traditional dance of Tigray. It involves a variety of steps, such as delicate neck motion, rhythmical shoulder movement, jumping steps, courting and so on. The physical demands of the dance classes were gradually increased, with the initial four weeks performed at a very light intensity. The program was taken sixteen (16) weeks three times per week. Each dance classes consisted of warm-up, main dance and cooldown sections, with music used to increase enjoyment and aid in highlighted various movement dynamics. The warm-up was lasted for 10 minutes and involved gentle joint mobility, alignment, body awareness and weight transference activities, as well as opportunities for individual choice and expression. The main dance section was lasted 40 minutes and consists of increasingly complex traditional dance movements that offered varied dynamic and expressive phrasing of the upper and lower body. These provided accumulative complexity e.g. awareness of space, directional change, and use of levels which were progressed from the warm-up and include partner dancing and social interaction.

The intensity of the participants was managed by counting their heart rate during the dance training. The cool-down lasted 5 minutes and involved gentle movements of the major bodily joints as well as deep and slow inhalation and exhalation respiration cycles. The participants of the control group were not allowed to participate in any of the training programs. However, all the participants of different training groups and control group were participated in their routine activities of the school. 


\section{Collection of Data}

After obtaining Ethical consideration from Ethical Review committee of Ayder Referral Hospital of Mekelle University and permission from administrators, students and experts, all the necessary information about the study was explained to the participants in well advance. All participants were oriented to be ready for the pre-test in the selected health-related physical fitness variables. Having experts, instruments and facilities for measuring purpose necessary data was collected with standardized procedure in both the pre and post-tests.

\section{Statistical Analyses}

The data collected were analysed statistically using SPSS 23 statistical software under the guidance of a statistician. Descriptive statistics such as mean and standard deviation were found in order to get the basic idea of the data distribution. The significance of adjusted posttest mean differences between the experimental and control group for each variable ANOVA (Analysis of variance) test was used. Scheffe's test was used to determine which of the paired means differed significantly. Level of significant was set at 0.05 .

\section{Results}

The following tables illustrate the statistical results as an effect of Traditional dances of Tigray regional state on muscular strength, flexibility, cardiovascular endurance and body composition among high school students.

\begin{tabular}{lll}
$\begin{array}{lll}\text { Table } \mathbf{1} \\
\text { Variables and criterion measures. }\end{array}$ & Units \\
\hline Variables & Tests/tools used & Count/30 sec \\
\hline Muscular strength & Sit-Ups (Davis, 2000). & Cms \\
Flexibility & Shoulder flexibility test (Wood, 2010). & Seconds \\
Cardiovascular endurance & Running test (1000m for boys and 800m for girls) (Wood, 2010). & $\mathrm{Kg} / \mathrm{m}^{2}$ \\
Body mass index & Weight and height & \\
\hline
\end{tabular}

Table 2

Analysis of variance for the pre -test and post- test data on muscular strength, flexibility, cardiovascular endurance and body composition score of Awris, Hura, Kuda, Shediva and control groups.

\begin{tabular}{llcccccc}
\hline Variables & Tests & Awris & Hura & Kuda & Shediva & Control Group \\
\hline Muscular Strength & PrT & $16.00 \pm 4.75$ & $14.25 \pm 5.42$ & $13.90 \pm 4.22$ & $12.30 \pm 2.88$ & $13.55 \pm 3.87$ & 1.924 \\
& PoT & $19.10 \pm 4.52$ & $17.10 \pm 5.73$ & $16.55 \pm 4.19$ & $15.90 \pm 2.82$ & $13.70 \pm 4.09$ & $4.005^{*}$ \\
& APT & 17.127 & 16.853 & 16.649 & 17.577 & 14.144 & $35.494^{*}$ \\
Flexibility & PrT & $35.10 \pm 10.02$ & $27.55 \pm 13.31$ & $35.95 \pm 9.19$ & $30.65 \pm 13.91$ & $28.35 \pm 14.26$ & 1.942 \\
& PoT & $31.05 \pm 9.25$ & $25.55 \pm 12.99$ & $33.75 \pm 9.00$ & $27.95 \pm 13.80$ & $28.05 \pm 14.42$ & $21.954^{*}$ \\
& APT & 27.549 & 29.433 & 29.417 & 28.801 & 31.150 & $20.437^{*}$ \\
Cardiovascular & PrT & $2.82 \pm 18.92$ & $2.60 \pm 31.29$ & $2.71 \pm 26.58$ & $2.70 \pm 24.69$ & $2.77 \pm 35.21$ & 1.781 \\
Endurance & PoT & $2.36 \pm 33.68$ & $2.23 \pm 32.44$ & $2.28 \pm 39.32$ & $2.34 \pm 32.49$ & $2.67 \pm 34.41$ & $4.963^{*}$ \\
& APT & 2.284 & 2.330 & 2.299 & 2.360 & 2.631 & $5.848^{*}$ \\
Body Composition & PrT & $18.32 \pm 2.77$ & $18.05 \pm 2.08$ & $18.38 \pm 2.47$ & $18.38 \pm 2.70$ & $18.61 \pm 2.92$ & 0.116 \\
& PoT & $17.29 \pm 2.59$ & $16.92 \pm 2.08$ & $17.64 \pm 2.57$ & $17.24 \pm 2.69$ & $18.51 \pm 2.82$ & 1.122 \\
& APT & 17.315 & 17.211 & 17.612 & 17.216 & 18.260 \\
\hline
\end{tabular}

PrT: Pretest; PoT: Posttest; APT: Adjusted Posttest; $F(4,95 ; 4,94)=2.46 ;{ }^{*} p<.05$. 


\section{Table 3}

Scheffe's test for differences of the adjusted post-test paired means of muscular strength, flexibility and cardiovascular endurance.

\begin{tabular}{|c|c|c|c|c|c|c|c|}
\hline \multirow{2}{*}{ Variables } & \multicolumn{5}{|c|}{ Adjusted Posttest Mean } & \multirow[t]{2}{*}{ MD } & \multirow[t]{2}{*}{$\mathrm{Cl}$} \\
\hline & Awris & Hura & Kuda & Shediva & Control Group & & \\
\hline Muscular & 17.127 & 16.853 & & & & 0.274 & 0.32 \\
\hline \multirow[t]{9}{*}{ Strength } & 17.127 & & 16.649 & & & $0.478^{*}$ & \\
\hline & 17.127 & & & 17.577 & & $0.450 *$ & \\
\hline & & 16.853 & 16.649 & & & 0.204 & \\
\hline & & & 16.649 & & 14.144 & $2.505^{*}$ & \\
\hline & & & & 17.577 & 14.144 & $3.433^{*}$ & \\
\hline & 17.127 & & & & 14.144 & $2.983^{*}$ & \\
\hline & & 16.853 & & & 14.144 & $2.709 *$ & \\
\hline & & & 16.649 & 17.577 & & $0.928^{*}$ & \\
\hline & & 16.853 & & 17.577 & & $0.724 *$ & \\
\hline \multirow[t]{10}{*}{ Flexibility } & 27.549 & 29.433 & & & & $1.884^{*}$ & 0.40 \\
\hline & 27.549 & & 29.417 & & & $1.868^{*}$ & \\
\hline & 27.549 & & & 28.801 & & $1.252^{*}$ & \\
\hline & & 29.433 & 29.417 & & & 0.016 & \\
\hline & & 29.433 & & 28.801 & & $0.632^{*}$ & \\
\hline & & & 29.417 & & 31.15 & $1.733^{*}$ & \\
\hline & & & & 28.801 & 31.15 & $2.349 *$ & \\
\hline & 27.549 & & & & 31.15 & $3.601^{*}$ & \\
\hline & & 29.433 & & & 31.15 & $1.717^{*}$ & \\
\hline & & & 29.417 & 28.801 & & $0.616^{*}$ & \\
\hline Cardiovascular & 2.236 & 2.33 & & & & 4.583 & 8.37 \\
\hline \multirow[t]{9}{*}{ Endurance } & 2.236 & & 2.299 & & & 1.540 & \\
\hline & 2.236 & & & 2.36 & & 7.630 & \\
\hline & & 2.33 & 2.299 & & & 3.043 & \\
\hline & & & 2.299 & & 2.631 & $33.206^{*}$ & \\
\hline & & & & 2.36 & 2.631 & $27.116^{*}$ & \\
\hline & 2.236 & & & & 2.631 & $34.746^{*}$ & \\
\hline & & 2.33 & & & 2.631 & $30.163 *$ & \\
\hline & & & 2.299 & 2.36 & & 6.090 & \\
\hline & & 2.33 & & 2.36 & & 3.047 & \\
\hline
\end{tabular}

${ }^{*} p<.05$ level; Cl: Confidence Interval; MD: Mean Differences

Table 2 indicates that the Traditional dance treatment groups had shown significant improvement in health-related physical fitness variables namely muscular endurance, flexibility, and cardiovascular endurance when compared with a control group as well as with the baseline data after they underwent sixteen weeks Traditional dance training program. However, no significant difference was observed in body composition. 
Moreover, Table 3 revealed that the adjusted post-test mean difference in muscular strength between Awris and control group, Hura and control group, Kuda and control group, Shediva and control group were 2.983, 2.709, 2.505 and 3.433 respectively which were greater than the confidence interval value 0.32 at 0.05 level of confidence, which indicating that, there was statistically significant difference among the treatment and control group. In addition statistically significant difference was observed among Awris and Kuda, Awris and Shediva, Kuda and Shediva, Hura and Shediva as the adjusted post-test mean difference $0.478,0.450$, 0.928 and 0.724 respectively were greater than the confidence interval value 0.32 at 0.05 level of confidence. Whereas the adjusted post-test mean difference in muscular strength between Awris and Hura and also between Hura and Kuda were 0.274 and 0.204 respectively which were less than the confidence interval value 0.32 at 0.05 level of confidence, which indicating that there was no significant difference among the groups.

The adjusted post-test mean difference in flexibility between Awris and control group, Hura and control group, Kuda and control group, Shediva and control group were 3.601, $1.717,1.733$ and 2.349 respectively which were greater than the confidence interval value 0.40 at 0.05 level of confidence, which indicating that, there was a statistically significant difference among the treatment and control group. In addition significant difference was observed among Awris and Hura, Awris and Kuda, Awris and Shediva, Hura and Shediva, Kuda and Shediva as the adjusted post-test mean difference $1.884,1.868,1.252,0.632$, and 0.616 respectively were greater than the confidence interval value 0.40 at 0.05 level of confidence. Whereas the adjusted post-test mean difference in flexibility between Hura and Kuda was 0.016 which was less than the confidence interval value 0.40 at 0.05 level of confidence, which indicating that, there was no significant difference among the group.

The adjusted post-test mean difference in cardiovascular endurance between Awris and control group, Hura and control group, Kuda and control group, Shediva and control group were 34.746, 30.163, 33.206 and 27.116 respectively which were greater than the confidence interval value 0.40 at 0.05 level of confidence, which indicating that, there was a statistically significant difference among the treatment and control group. Whereas the adjusted post-test mean difference in cardiovascular endurance between Awris and Hura, Awris and Kuda, Awris and Shediva, Hura and Kuda, Kuda and Shediva and Hura and Shediva were 4.583, 1.540, 7.630, 3.043, 6.090 and 3.047 respectively which were less than the confidence interval value 8.37 at 0.05 level of confidence, which indicating that, there was no significant difference among the groups.

\section{Discussion}

The main objective of the present study was to evaluate the effect of Traditional dances of Tigray regional state i.e.,Awris, Hura, Kuda and Shediva, on health-related physical fitness variables, namely, muscular strength, flexibility, cardiovascular endurance and body composition. As a result, the sixteen weeks traditional dance training program significantly improve the health-related physical fitness variables namely muscular strength, flexibility and cardiovascular endurance of high school students. This is maybe because exercise enhances muscular strength by hypertrophy, or the enlargement of muscle cells, and also creates neural adaptations that enhance the nervemuscle interaction (Mark, 2019). Besides, defined and structured training program increases the stroke volume and enhanced myocardial contractility and structurally, all the four heart chambers increased in volume with mild 
increases in wall thicknesses, resulting in greater cardiac mass due to increased myocardial cell size (Wilson et al., 2016).

The above result was in agreement with the following studies conducted by (Kim et al., 2018) proved that Korean traditional dance program improved the health-related fitness of Korean elderly females. Also, Biber (2016) proved that folk dance training significantly improved children"s physical fitness development. More ever (Vordos et al., 2017) revealed that traditional Greek dance significantly improves muscular strength and lower limb endurance.

However, no statistically significant difference was observed in body composition. This result may be due to the shorter interventional duration (Metcalf et al., 2011). In school age, the time spent in vigorous physical activity is strongly and independently associated with lower adiposity (Collings et al., 2012). Studies with a significantly reduction of BMI usually had interventional duration longer than 4 months (Ardoy et al., 2013; Salcedo Aguilar et al., 2010). In line with this the World Health Organization (WHO, 2010), recommends that school-aged children and youth accumulate at least $60 \mathrm{~min}$ of moderate-to-vigorous intensity physical activity every day for health benefits.

The above result was in agreement with the following studies conducted by Kim et al., (2018) have proved that traditional dance could not improve the body mass index of high school students. Also, Belle et al. (1983) revealed that aerobic dance without dietary control does not alter body composition in sedentary middleaged women.

\section{Conclusion}

Within the limitations of the present study, it was concluded that, the Traditional dance treatment groups had shown significant improvement in the studied health-related physical fitness variables namely muscular endurance, flexibility and cardiovascular endurance when compared with the control group as well as the base line information after they underwent 16-weeks of Tigray Traditional dance practicing. However, no significant difference was observed in body composition. So, it can be concluded that, Tigray Region Traditional dances (Awris, Hura, Kuda and Shediva) can be improve the health-related physical fitness variables of high school students.

\section{Acknowledgments}

The researchers wish to acknowledge the Department of Sport Science, College of Natural and Computational Sciences and Mekelle University for the support and approval to carry out the study. We also appreciate the enthusiasm and co-operation of the participants. All authors searched the literature and wrote, revised and approved the manuscript.

\section{Conflict of Interest}

The authors declared no potential conflicts of interest concerning the research, authorship, and/or publication of this article.

\section{References}

American College of Sports Medicine. (1998). American College of Sports Medicine position stand: exercise and physical activity for older adults. Med Sci Sports Exerc, 30(6), 992-1008.

Ardoy, D.N., Artero, E.G., Ruiz, J.R., Labayen, I., Sjöström, M., Castillo, M.J., \& Ortega, F.B. (2013). Effects on adolescents' lipid profile of a fitnessenhancing intervention in the school setting; the EDUFIT study. Nutr Hosp, 28(1), 119-126.

Belle, D.D. (1983). The effect of aerobic dance on physical work capacity, cardiovascular function and body composition of middle aged women. Diss Abstr Int, 43, 3535.

Biber, K. (2016). The effects of folk dance training on 5- 6 years children's physical and social 
development. Journal of Education and Training Studies, 4(11), 213-226.

Biddle, S.J., Gorely, T., \& Stensel, D.J. (2004). Healthenhancing physical activity and sedentary behaviour in children and adolescents. J Sports Sci, 22(8), 679-701.

Collings, P. J., Brage, S., Ridgway, C. L., Harvey, N. C., Godfrey, K. M., Inskip, H. M., Cooper, C., Wareham, N. J., \& Ekelund, U. (2013). Physical activity intensity, sedentary time, and body composition in preschoolers. Am J Clin Nutr, 97(5), 1020-1028.

Urmston, E., Chater, A., Spampinato-Korn, A., \& Kozub, S. (2012). Inspiring children to dance to 2012 and beyond. Go Dance Research Report, Ipswich, Suffolk, UK.

Public Health - South West. (2020). Cool Facts - Hot Feet: dancing to health: a review of the evidence, 2011. Retrieved from https://www.communitydance.org.uk/DB/resourc es-3/cool-facts-hot-feet-dancing-to-health-areview-of-

Gardner, S., Komesaroff, P., \& Fensham, R. (2008). Dancing beyond exercise: young people's experiences in dance classes. Journal of Youth Studies, 11(6), 701-709.

Kim, S., Park, H., Min, B., \& So, W. (2018). Effects of a Korean traditional dance program on healthrelated fitness and blood lipid profiles in Korean elderly females, 47(1), 127-129.

Almond, L. (2010). The place of physical education. London: Kogan Page Ltd.

Georgios, L., Ioannis, G., Olga, T., Dimitris, C., \& Maria, K. (2017). The effect of a traditional dance program on health-related quality of life as perceived by primary school students. Journal of Education and Training Studies, 6(1), 96-103.

Farr, M. (1997). The role of dance/movement therapy in treating at-risk African American adolescents. The Arts in Psychotherapy, 24(2), 183-191.

Tensay, M.G., Hassrani, S.S., \& Mukherjee, S. (2015). Effect of different traditional dances of Tigray region on selected physical fitness triad on collegiate youths. International Journal of Innovation
Sciences and Research, 4(4), 129-138.

Andrews, M.A.W. (2019, December 20). How does exercise make your muscles stronger? (October 27, 2003). Retrieved from https://www.scientificamerican.com/article/howdoes-exercise-make-yo/

Marquez, D.X., Wilbur, J.E., Hughes, S.L., Berbaum, M.L., Wilson, R.S., Buchner, D.M., \& McAuley, E. (2014). B.A.I.L.A. - a Latin dance randomized controlled trial for older Spanish-speaking Latinos: rationale, design, and methods. Contemporary Clinical Trials, 38(2), 397-408.

Metcalf, B.S., Hosking, J., Jeffery, A.N., Voss, L.D., Henley, W., \& Wilkin, T.J. (2011). Fatness leads to inactivity, but inactivity does not lead to fatness: a longitudinal study in children (EarlyBird 45). Arch Dis Child, 96(10), 942-947.

Li, M., Fang, Q., Li, J., Zheng, X., Tao, J., Yan, X., Lin, Q., Lan, X., Chen, B., Zheng, G., \& Chen, L. (2015). The effect of Chinese Traditional ExerciseBaduanjin on physical and psychological wellbeing of college students: a randomized controlled trial. PLoS One, 10(7), e0130544.

Murrock, C.J., \& Gary, F.A. (2010). Culturally specific dance to reduce obesity in African American Women. Health Promotion Practice, 11(4), 465-473.

Nhamo, E., \& Magonde, S. (2013). Dance as a viable alternative to sport: Effects of traditional dances on the health and fitness of Zimbabwean women. Journal of Sports and Physical Education, 1(1), 20-28.

Nordin, S.M. \& Hardy, C. (2009). Dance4Health: a research-based evaluation of the impact of seven community dance projects on physical health, psychological wellbeing and aspects of social inclusion. Warwickshire, UK: County Arts Service.

Salcedo Aguilar, F., Martínez-Vizcaíno, V., Sánchez López, M., Solera Martínez, M., Franquelo Gutiérrez, R., Serrano Martínez, S., López-García, E., \& Rodríguez-Artalejo, F. (2010). Impact of an after-school physical activity program on obesity in children. J Pediatr, 2010 157(1), 36-42.e3.

Serrano-Guzman, M., Valenza-Pena, M.C., SerranoGuzman, C., Aguilar-Ferrandiz, E., ValenzaDemet, G., \& Villaverde-Gutiérrez, C. (2016). 
Effects of a dance therapy programme on quality of life, sleep and blood pressure in middle-aged women: a randomised controlled trial. Medicina Clínica (English Edition), 147(8), 334-339.

Thompson, S.K. (2012). Sampling. $3^{\text {rd }}$ Ed., New Jersey, USA: John Wiley \& Sons, Inc.

Kim, S.M., Park, H.J., Min, B.J., \& So, W.Y. (2018). Effects of a Korean traditional dance program on health-related fitness and blood lipid profiles in Korean elderly females. Iran J Public Health, 47(1), 127-129.

Vordos, Z., Kouidi, E., Mavrovouniotis, F., Metaxas,
T., Dimitros, E., Kaltsatou, A., \& Deligiannis, A. (2017). Impact of traditional Greek dancing on jumping ability, muscular strength and lower limb endurance in cardiac rehabilitation programmes. Eur J Cardiovasc Nurs, 16(2), 150-156.

Wilson, M.G., Ellison, G.M., \& Cable, N.T. (2016). Basic science behind the cardiovascular benefits of exercise. Br J Sports Med, 50, 93-99.

WHO. (2010). Word Health Organization. (WHO), Global Recommendations on Physical Activity for Health. Geneva, Switzerland: World Health Organization. 